\title{
Myroides pelagicus sp. nov., isolated from seawater in Thailand
}

Correspondence

Jaewoo Yoon

aa57058@mail.ecc.u-tokyo.ac.jp

\author{
Jaewoo Yoon, ${ }^{1}$ Suppasil Maneerat, ${ }^{2}$ Fusako Kawai $^{2}$ and Akira Yokota ${ }^{1}$ \\ 'Institute of Molecular and Cellular Biosciences, The University of Tokyo, 1-1-1 Yayoi, \\ Bunkyo-Ku, Tokyo 113-0032, Japan \\ ${ }^{2}$ Laboratory of Applied Microbiology, Research Institute for Bioresources, Okayama University, \\ 2-20-1 Chuo, Kurashiki, 710-0046, Japan
}

The genus Myroides was established by the reclassification of Flavobacterium odoratum as Myroides odoratus, the type species, on the basis of genomic, chemotaxonomic and phenotypic studies (Vancanneyt et al., 1996). Myroides odoratimimus was also described in the report. Currently, the genus Myroides comprises only these two species, both of which originated from clinical sources (Holmes et al., 1977). Strain $\mathrm{SM} 1^{\mathrm{T}}$ was obtained during the isolation of crude oilutilizing and -emulsifying bacteria from seawater (Maneerat et al., 2005). Strain $S M 1^{\mathrm{T}}$ and the two species of the genus Myroides were found to produce surface-active compounds in marine broth, which were identified as cholic acid, deoxycholic acid and their conjugates with glycine. These findings led to the first report indicating that bile acids can be produced by prokaryotic cells (Maneerat et al., 2005). In the present study, we attempted to elucidate the phylogenetic position of strain $\mathrm{SM}^{\mathrm{T}}$ using a polyphasic taxonomic approach, including $16 \mathrm{~S}$ rRNA gene sequence analysis, fatty acid content analysis, quinone analysis and genotypic ( $\mathrm{G}+\mathrm{C}$ content of DNA, DNA-DNA hybridization) and physiological comparisons. Based on these data, it is proposed that strain $\mathrm{SM} 1^{\mathrm{T}}$ represents a novel species in the genus Myroides.

Temperature range and $\mathrm{pH}$ range for growth were determined by incubating in Luria-Bertani (LB) medium (Atlas, 2004). Cell morphology was observed by microscopy (BX60; Olympus). Growth under anaerobic conditions was determined after 2 weeks incubation in an AnaeroPack (Mitsubishi

The GenBank/EMBL/DDBJ accession number for the 16S rRNA gene sequence of strain $\mathrm{SM}^{\top}{ }^{\top}$ is $\mathrm{AB} 176662$.
Gas). Catalase activity was determined by bubble formation in $3 \% \mathrm{H}_{2} \mathrm{O}_{2}$ solution. Oxidase activity was determined by cytochrome oxidase paper (Nissui Pharmaceutical). API 20E and API ZYM strips (bioMérieux) were used to determine physiological and biochemical characteristics. API 20E and API ZYM were read after $48 \mathrm{~h}$ incubation at $28^{\circ} \mathrm{C}$ and $4 \mathrm{~h}$ incubation at $37^{\circ} \mathrm{C}$, respectively. The nutritional features of strain $\mathrm{SM}^{\mathrm{T}}$ and M. odoratimimus JCM $7460^{\mathrm{T}}$ and M. odoratus JCM $7458^{\mathrm{T}}$ were determined using Biolog MicroPlates. The strains were grown on BUG medium (Biolog, supplemented with $5 \mathrm{ml}$ sterile sheep blood $\mathrm{l}^{-1}$ ) at $28{ }^{\circ} \mathrm{C}$ for $24 \mathrm{~h}$ and suspended in sterile saline medium within the density range specified by the manufacturer with a photometer (21907; Biolog). Immediately after suspending the cells in saline solution, suspensions were transferred to sterile multichannel pipetter reservoirs (Biolog) and GN2 MicroPlates (Biolog) were inoculated with $150 \mu \mathrm{l}$ cell suspension per well by using an eight-channel repeating pipetter (Biolog). The inoculated plates were incubated at $28^{\circ} \mathrm{C}$ for $6 \mathrm{~h}$ and the results were read with a MicroPlate Reader using MICROLOG 3.59 software to perform automated reading.

Determination of the respiratory quinone system and cellular fatty acid content (MIDI) were carried out as described previously (Xie \& Yokota, 2003). DNA was prepared according to the method of Marmur (1961) from cells grown on LB medium and DNA G $+\mathrm{C}$ content was determined by using the HPLC method of Mesbah et al. (1989). DNA-DNA hybridizations were carried out with photobiotin-labelled probes in microplate wells as described by Ezaki et al. (1989). The hybridization temperature was $40^{\circ} \mathrm{C}$. An approximately 
1500-bp fragment of the 16S rRNA gene was amplified from the extracted DNA using bacterial universal primers specific to the $16 \mathrm{~S}$ rRNA gene, primer $8 \mathrm{~F}, 5^{\prime}$-AGAGTTTGATCCTGGCTCAG-3' [positions 8-27, according to the Escherichia coli numbering system of Brosius et al. (1978)], and primer 1510R, 5'-GGCTACCTTGTTACGTA-3' (positions 1510-1527). PCR and sequencing protocols have been previously described (Xie \& Yokota, 2003).

The 16S rRNA gene sequence of strain $\mathrm{SM} 1^{\mathrm{T}}$ was compared with sequences obtained from GenBank. Sequences were aligned with CLUSTAL W software (Thompson et al., 1994) and evolutionary distances and the $K_{\text {nuc }}$ value (Kimura, 1980) were generated. Alignment gaps and ambiguous bases were not taken into consideration when the 1317 bases of $16 \mathrm{~S}$ rRNA gene nucleotides were compared. A phylogenetic tree was constructed using the neighbour-joining method (Saitou \& Nei, 1987). The topology of the phylogenetic tree was evaluated by the bootstrap resampling method of Felsenstein (1985) with 1000 replicates. Similarity values were calculated using PAUP 4.0b1 (Swofford, 1998).

The 16S rRNA gene sequence of strain $\mathrm{SM}^{\mathrm{T}}$ showed the highest similarities to the sequences of $M$. odoratimimus JCM $7460^{\mathrm{T}}(95 \cdot 8 \%)$ and M. odoratus JCM $7458^{\mathrm{T}}(93 \cdot 8 \%)$, but low sequence similarity (less than $90 \%$ ) with other genera. The phylogenetic tree in Fig. 1 shows that strain $\mathrm{SM}^{\mathrm{T}}$ was clustered within the genus Myroides with $100 \%$ bootstrap support. DNA-DNA hybridization values between strain $\mathrm{SM1}^{\mathrm{T}}$ and $M$. odoratimimus JCM $7460^{\mathrm{T}}$ and M. odoratus JCM $7458^{\mathrm{T}}$ were $22 \cdot 0$ and $26 \cdot 0 \%$, respectively. These results indicate that strain $S M 1^{\mathrm{T}}$ represents a separate species of the genus Myroides (Stackebrandt \& Goebel, 1994).

Chemotaxonomic analysis further supported the phylogenetic results. The major quinone system of strain $\mathrm{SM}^{\mathrm{T}}$ was
Table 1. Cellular fatty acid content (\%) of Myroides pelagicus sp. nov. and other species of the genus Myroides

Values are percentages of total fatty acids. Values $<1 \%$ are not shown. Taxa: 1, M. pelagicus sp. nov.; 2, M. odoratimimus JCM $7460^{\mathrm{T}} ; 3$, M. odoratus JCM $7458^{\mathrm{T}}$. tr, Trace.

\begin{tabular}{|lrcc|}
\hline Fatty acid & $\mathbf{1}$ & $\mathbf{2}$ & $\mathbf{3}$ \\
\hline $\mathrm{C}_{13: 0}$ iso & $7 \cdot 4$ & $1 \cdot 8$ & $\operatorname{tr}$ \\
$\mathrm{C}_{15: 0}$ iso & $49 \cdot 4$ & $43 \cdot 3$ & $45 \cdot 5$ \\
$\mathrm{C}_{15: 0}$ anteiso & $1 \cdot 0$ & $1 \cdot 0$ & $2 \cdot 0$ \\
$\mathrm{C}_{15: 0}$ iso 3-OH & $6 \cdot 1$ & $5 \cdot 8$ & $5 \cdot 8$ \\
$\mathrm{C}_{16: 0} 3-\mathrm{OH}$ & $2 \cdot 8$ & $4 \cdot 0$ & $1 \cdot 5$ \\
$\mathrm{C}_{16: 1} \omega 7 c / \mathrm{C}_{15}$ iso 2-OH & $1 \cdot 9$ & $3 \cdot 6$ & $\operatorname{tr}$ \\
$\mathrm{C}_{17: 0}$ iso 3-OH & $10 \cdot 1$ & $12 \cdot 5$ & $21 \cdot 2$ \\
$\mathrm{C}_{17: 1} \omega 9 c$ iso & $13 \cdot 1$ & $15 \cdot 1$ & $13 \cdot 8$ \\
\hline
\end{tabular}

menaquinone MK-6. Major fatty acids of strain $\mathrm{SM}^{\mathrm{T}}$ were $\mathrm{C}_{15: 0}$ iso $(49 \cdot 4 \%), \mathrm{C}_{17: 1} \omega 9 \mathrm{c}$ iso $(13 \cdot 1 \%)$ and $\mathrm{C}_{17: 0}$ iso 3$\mathrm{OH}(10 \cdot 1 \%)$, which is similar to other members of the genus Myroides (Table 1). The DNA G $+\mathrm{C}$ content of strain $\mathrm{SM}^{\mathrm{T}}$ was $33.6 \mathrm{~mol} \%$.

Strain $\mathrm{SM} 1^{\mathrm{T}}$ could be distinguished from the other species of the genus Myroides by various phenotypic characteristics (Table 2). Strain $\mathrm{SM}^{\mathrm{T}}$ was isolated from seawater and could tolerate $9 \% \mathrm{NaCl}$; the other species of the genus Myroides, originating from clinical sources, could only tolerate $5-6 \% \mathrm{NaCl}$. Moreover, strain $\mathrm{SM}^{\mathrm{T}}$ could also be distinguished by the following characteristics: negative results for catalase and urease activities, no nitrate reduction and no activities for esterase (C4) and esterase lipase (C8). Some differential characteristics were also obtained from the Biolog results, including positive results for strain $\mathrm{SM}^{\mathrm{T}}$ for the utilization of $\alpha$-hydroxybutyric and succinamic acids and negative results for the utilization of L-histidine and urocanic acid.

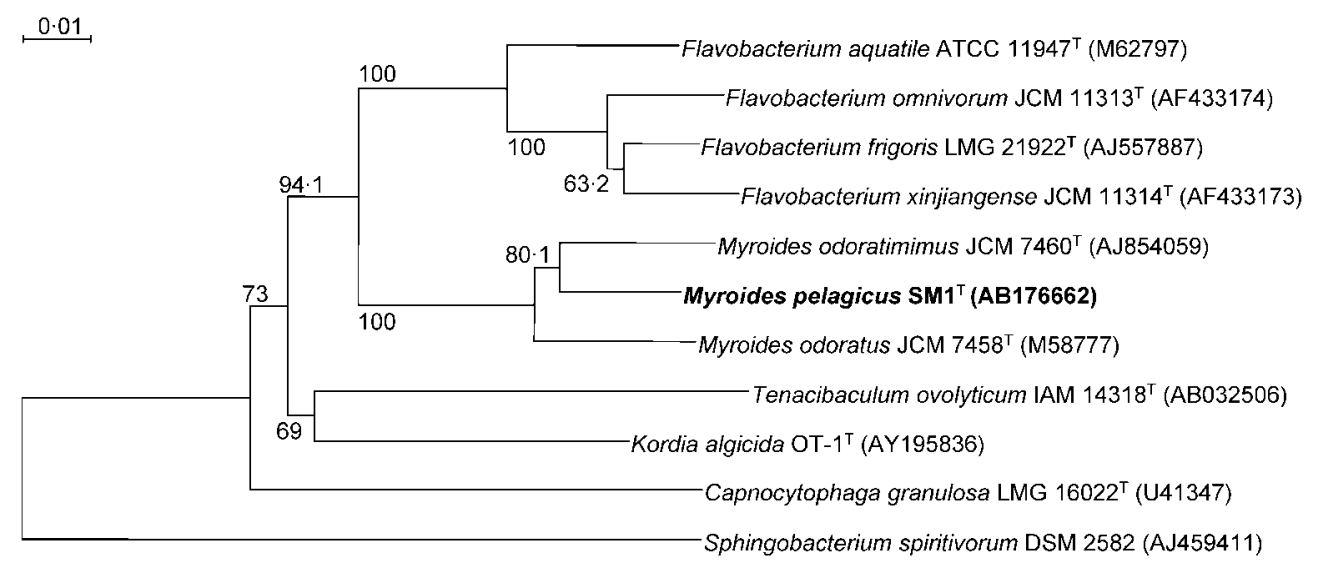

Fig. 1. A neighbour-joining phylogenetic tree of a subset of the genus Myroides and representatives of some other taxa based on 16S rRNA gene sequence comparisons. Sphingobacterium spiritivorum DSM 2582 was used as the outgroup. Bootstrap percentages above $60 \%$ (from 1000 replicates) are shown at nodes. Bar, 0.01 nucleotide substitutions per site. 
Table 2. Differential characteristics of Myroides pelagicus sp. nov. and related Myroides species

Taxa: 1, M. pelagicus sp. nov.; 2, M. odoratimimus JCM $7460^{\mathrm{T}} ; 3$, M. odoratus JCM $7458^{\mathrm{T}}$. Data are from this and earlier studies (Holmes et al., 1977; Vancanneyt et al., 1996; Maneerat et al., 2005). +, Positive; w, weakly positive; -, negative.

\begin{tabular}{|lccc|}
\hline Characteristic & $\mathbf{1}$ & $\mathbf{2}$ & $\mathbf{3}$ \\
\hline Source & Seawater & Wound swab & Faeces \\
Cell morphology & Short rods & Rods & Long rods \\
Cell diameter $(\mu \mathrm{m})$ & $0 \cdot 5-1$ & $3 \cdot 5-4$ & $11-12$ \\
Cell width $(\mu \mathrm{m})$ & $0 \cdot 2-0 \cdot 3$ & $0 \cdot 2-0 \cdot 3$ & $0 \cdot 2-0 \cdot 3$ \\
Pigmentation & Yellow-to-orange & Pale-yellow & Yellow \\
NaCl range $(\%$, w/v) & $0-9$ & $0-6$ & $0-5$ \\
pH range & $5-9$ & $6-9$ & $6-9$ \\
Catalase & w & + & + \\
Urease & - & + & + \\
Nitrate reduction & - & + & + \\
Activity of: & & + & + \\
Esterase $(C 4)$ & - & + & + \\
Esterase lipase $(\mathrm{C} 8)$ & - & & + \\
Utilization of: & & - & + \\
L-Histidine & - & W & + \\
$\alpha$-Hydroxybutyric acid & + & $31 \cdot 7$ & + \\
Succinamic acid & + & & $34 \cdot 7$ \\
Urocanic acid & - & & + \\
DNA G+C content $($ mol\%) & $33 \cdot 6$ & & + \\
\hline
\end{tabular}

On the basis of phenotypic and phylogenetic characteristics, strain $\mathrm{SM}^{\mathrm{T}}$ could be assigned as representing a separate species of the genus Myroides. We therefore propose the name Myroides pelagicus sp. nov. for strain $\mathrm{SM}^{\mathrm{T}}$.

\section{Description of Myroides pelagicus sp. nov.}

Myroides pelagicus (pe.la'gi.cus. L. masc. adj. pelagicus belonging to the sea).

Cells are Gram-negative, aerobic, straight, short and single rods $(0 \cdot 5-1 \times 0 \cdot 2-0 \cdot 3 \mu \mathrm{m})$. Cells lack flagella. Neither cellular gliding movement nor swarming growth are observed. Colonies grown on LB agar medium are circular, convex and yellow-to-orange. The temperature range for growth is $10-37^{\circ} \mathrm{C}$; no growth occurs at 4 or $45^{\circ} \mathrm{C}$. The $\mathrm{pH}$ range for growth is $5 \cdot 0-9 \cdot 0 . \mathrm{NaCl}$ is not required for growth, but is able to tolerate up to $9.0 \% \mathrm{NaCl}(\mathrm{w} / \mathrm{v})$. Catalase reaction is weakly positive, whereas oxidase reaction is positive. Gelatin hydrolysis, Voges-Proskauer test and citrate utilization results are positive, but activities of ONPG, arginine dihydrolase, lysine decarboxylase, ornithine decarboxylase and urease, production of hydrogen sulfide and indole and reduction of nitrate and nitrite are negative. Positive results for activities of alkaline phosphatase, leucine arylamidase, acid phosphatase and naphthol-AS-BI-phosphohydrolase, but negative results for esterase (C4), esterase lipase (C8), lipase (C4), valine arylamidase, cystine arylamidase, trypsin, chymotrypsin, $\alpha$-galactosidase, $\beta$-galactosidase, $\alpha$-glucosidase, $\beta$-glucosidase and tryptophan deaminase. Glycogen, methyl pyruvate, monomethyl succinate, acetic acid, $\alpha$-ketoglutaric acid, $\alpha$-ketovaleric acid, DL-lactic acid, succinic acid, bromosuccinic acid, succinamic acid, L-alanine, L-alanyl glycine, L-asparagine, L-aspartic acid, L-glutamic acid, glycyl L-aspartic acid, glycyl L-glutamic acid, L-leucine, L-ornithine, L-proline, L-serine, L-threonine, inosine, uridine and thymidine are utilized, but cyclodextrin, dextrin, Tween 40, Tween 80, N-acetyl-D-glucosamine, $N$-acetyl-Dgalactosamine, adonitol, L-arabinose, D-arabitol, cellobiose, $i$-erythritol, D-fructose, L-fucose, D-galactose, gentiobiose, $\alpha$-D-glucose, myo-inositol, $\alpha$-D-lactose, lactulose, maltose, D-mannitol, D-mannose, D-melibiose, methyl $\beta$-D-glucoside, D-psicose, D-raffinose, L-rhamnose, D-sorbitol, sucrose, D-trehalose, furanose, xylitol, cis-aconitic acid, citric acid, formic acid, D-galactonic acid lactone, D-galacturonic acid, D-gluconic acid, D-glucosaminic acid, D-glucuronic acid, $\alpha$-hydroxybutyric acid, $\gamma$-hydroxybutyric acid, $p$-hydroxyphenylacetic acid, itaconic acid, $\alpha$-ketobutyric acid, malonic acid, propionic acid, quinic acid, D-saccharic acid, sebacic acid, glucuronamide, alaninamide, D-alanine, L-histidine, hydroxyl-L-proline, L-phenylalanine, L-pyroglutamic acid, D-serine, DL-carnitine, $\gamma$-aminobutyric acid, urocanic acid, phenylethylamine, putrescine, 2-aminoethanol, 2,3-butanediol, glycerol DL- $\alpha$-glycerol phosphate, glucose 1-phosphate and D-glucose 6-phosphate are not utilized. The major quinone system is menaquinone MK-6. The major cellular fatty acids are $\mathrm{C}_{15: 0}$ iso, $\mathrm{C}_{17: 1} \omega 9 c$ iso and $\mathrm{C}_{17: 0}$ iso $3-\mathrm{OH}$. The $\mathrm{DNA} \mathrm{G}+\mathrm{C}$ content of the type strain is $33.6 \mathrm{~mol} \%$. 
The type strain, $\mathrm{SM1}^{\mathrm{T}}\left(=\mathrm{IAM} 15337^{\mathrm{T}}=\mathrm{KCTC} 12661^{\mathrm{T}}\right)$, was isolated from seawater, off the coast of Thailand.

\section{References}

Atlas, R. M. (2004). Handbook of Microbiological Media, 3rd edn. Boca Raton, FL: CRC Press.

Brosius, J., Palmer, M. L., Kennedy, P. J. \& Noller, H. F. (1978). Complete nucleotide sequence of a $16 \mathrm{~S}$ ribosomal RNA gene from Escherichia coli. Proc Natl Acad Sci U S A 75, 4801-4805.

Ezaki, T., Hashimoto, Y. \& Yabuuchi, E. (1989). Fluorometric deoxyribonucleic acid-deoxyribonucleic acid hybridization in microdilution wells as an alternative to membrane filter hybridization in which radioisotopes are used to determine genetic relatedness among bacterial strains. Int J Syst Bacteriol 39, 224-229.

Felsenstein, J. (1985). Confidence limits on phylogenies: an approach using the bootstrap. Evolution 39, 783-791.

Holmes, B., Snell, J. J. S. \& Lapage, S. P. (1977). Revised description, from clinical isolates, of Flavobacterium odoratum Stutzer and Kwaschnina 1929, and designation of the neotype strain. Int J Syst Bacteriol 27, 330-336.

Kimura, M. (1980). A simple method for estimating evolutionary rates of base substitutions through comparative studies of nucleotide sequences. J Mol Evol 16, 111-120.

Maneerat, S., Nitoda, T., Kanzaki, H. \& Kawai, F. (2005). Bile acids are new products of a marine bacterium, Myroides sp. strain SM1. Appl Microbiol Biotechnol 67, 679-683.
Marmur, J. (1961). A procedure for the isolation of deoxyribonucleic acid from microorganisms. J Mol Biol 3, 208-218.

Mesbah, M., Premachandran, U. \& Whitman, W. B. (1989). Precise measurement of the $\mathrm{G}+\mathrm{C}$ content of deoxyribonucleic acid by high-performance liquid chromatography. Int J Syst Bacteriol 39, 159-167.

Saitou, N. \& Nei, M. (1987). The neighbor-joining method: a new method for reconstructing phylogenetic trees. Mol Biol Evol 4, 406-425.

Stackebrandt, E. \& Goebel, B. M. (1994). Taxonomic note: a place for DNA-DNA reassociation and 16S rRNA sequence analysis in the present species definition in bacteriology. Int J Syst Bacteriol 44, 846-849.

Swofford, D. L. (1998). PAUP* - Phylogenetic analysis using parsimony (*and other methods), version 4 . Sunderland, MA: Sinauer Associates.

Vancanneyt, M., Segers, P., Torck, U., Hoste, B., Bernardet, J.-F., Vandamme, P. \& Kersters, K. (1996). Reclassification of Flavobacterium odoratum (Stutzer 1929) strains to a new genus, Myroides, as Myroides odoratus comb. nov. and Myroides odoratimimus sp. nov. Int J Syst Bacteriol 46, 926-932.

Thompson, J. D., Higgins, D. G. \& Gibson, T. J. (1994). CLUSTAL W: improving the sensitivity of progressive multiple sequence alignment through sequence weighting, position-specific gap penalties and weight matrix choice. Nucleic Acids Res 22, 4673-4680.

Xie, C. H. \& Yokota, A. (2003). Phylogenetic analyses of Lampropedia hyalina based on the 16S rRNA gene sequence. J Gen Appl Microbiol 49, 345-349. 